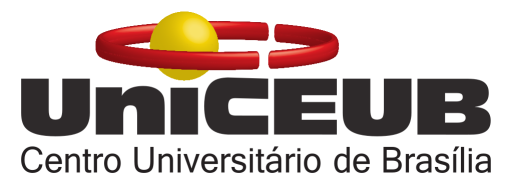

CENTRO UNIVERSITÁRIO DE BRASÍLIA - UnICEUB

PROGRAMA DE INICIAÇÃO CIENTÍFICA

LUCAS VENZI GONÇALVES DE MORAES

DESEMPENHO TÉRMICO E LUMÍNICO INTERNO E EXTERNO DE VIDRO COM PELÍCULA DE POLIVINIL BUTIRAL EM AMBIENTE DE ESCALA REDUZIDA

BRASÍLIA

2018 


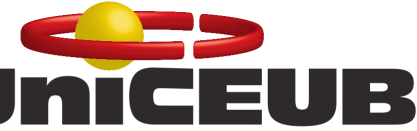 \\ Centro Universitário de Brasília}

\section{LUCAS VENZI GONÇALVES DE MORAES}

\section{DESEMPENHO TÉRMICO E LUMÍNICO INTERNO E EXTERNO DE VIDRO COM PELÍCULA DE POLIVINIL BUTIRAL EM AMBIENTE DE ESCALA REDUZIDA}

Relatório final de pesquisa de Iniciação Científica apresentado à Assessoria de Pós-Graduação e Pesquisa pela Faculdade de Tecnologia e Ciências Sociais aplicadas - FATECS

Orientação: Prof. Dr. Marcos Rafael Guassi 


\section{Dedicatória}

Dedico esta, aos meus pais, Marcelo e Edna, meus irmãos e familiares por acreditarem até o fim, sempre, na minha capacidade de realizações e investirem em mim.

À Rachel, pelo apoio e incentivo, em todos os momentos, dos mais fáceis aos piores. Aos amigos, pela constante parceria e aos meus professores que me deram instrução. 


\section{Agradecimentos}

A este Centro Universitário, UniCEUB, pela oportunidade de cursar engenharia civil com excelência e realizar este projeto, proporcionar amplo aprendizado, e a bolsa adquirida durante a realização do mesmo. Sou grato a todo corpo docente, à direção e administração dessa instituição.

Ao Prof. Dr. Marcos, orientador do projeto, pelo empenho e paciência dedicado a ensinar e elaborar este projeto.

A todos que direta ou indiretamente fizeram parte da minha formação. 


\title{
DESEMPENHO TÉRMICO E LUMÍNICO INTERNO E EXTERNO DE VIDRO COM PELÍCULA DE POLIVINIL BUTIRAL EM AMBIENTE DE ESCALA REDUZIDA
}

\author{
Lucas Venzi Gonçalvez de Moraes - UniCEUB, PIC Instituional, aluno bolsista \\ lucas.venzi@sempreceub.com
}

Marcos Rafael Guassi - UniCEUB, professor orientador marcos.guassi@ceub.edu.br

A utilização de diferentes películas em diferentes cores de vidro alteram não só a arquitetura da fachada dos edifícios mas também o seu desempenho térmico e lumínico, e estes influenciam diretamente na temperatura do ambiente e exposição a raios ultravioletas. O objetivo deste trabalho foi comparar a diferença de temperatura interna e externa e a luminosidade refletida e transmitida para inferir a influência das cores dos vidros e tipos de películas em um ambiente simulado em escala reduzida. Para tal, utilizou-se ambientes reduzidos feitos de madeirite e com isolamento de isopor. Na parte frontal foram colocados os vidros com suas respectivas películas, e com uma câmara térmica foram medidas temperaturas de cada um. Com um luxímetro, mediu-se as luminosidades internas, refletidas próximas aos vidros e em uma posição deslocada dos vidro, com intuito de comparar esses valores. As medidas foram feitas sistematicamente ao longo do período da tarde e durante os meses de outono e inverno, quando o Sol apresenta maior declinação ao norte. Foram feitos dois tipos de medidas para tentar eliminar os parâmetros ambientais que poderiam viciar as medidas. Percebeu-se, como esperado, que o ambiente com vidro transparente é aquele que possui temperaturas internas mais altas, na mesma temperatura do vidro. $\mathrm{O}$ vidro transparente com uma película com filtro de $75 \%$ de luz dissipa a maior parte da energia radiante do Sol por absorção (esquentando o vidro) e reflexão, fazendo com que grande parte da luminosidade seja devolvida ao meio externo, com o benefício de baixa temperatura interna. Por fim percebe-se que cada combinação entre os vidros disponíveis (transparente e verde) juntamente com diferentes películas (de $50 \%$ ou $75 \%$ de filtro) fornecem valores bastante diferentes, mostrando que é importante uma análise aprofundada do que cada obra pretende priorizar. 


\section{Lista de Figuras}

3.1 Representação em planta baixa das caixas que compõe o ambiente em escala reduzida. ...................... 6

3.2 Esboço da disposição e numeração dos ambientes em escala reduzida. 7

4.1 Luminosidade interna medida no ambiente de escala reduzida, para cada vidro, utilizando-se da metodologia 1. . . . . . . . . . . . . . . . . 10

4.2 Luminosidade interna medida no ambiente de escala reduzida, para cada vidro, utilizando-se da metodologia 2. . . . . . . . . . . . . . . . . 10

4.3 Luminosidade refletida por cada vidro, utilizando-se da metodologia 1. 11

4.4 Luminosidade refletida por cada vidro, utilizando-se da metodologia 2. . 12

4.5 Comparação entre a temperatura do vidro e a interna do ambiente 1 . . 12

4.6 Comparação entre a temperatura do vidro e a interna do ambiente 2 . . 13

4.7 Comparação entre a temperatura do vidro e a interna do ambiente 3 . . 13

4.8 Comparação entre a temperatura do vidro e a interna do ambiente 4 . . 14

4.9 Comparação entre a temperatura do vidro e a interna do ambiente 5 . . 14

4.10 Comparação entre a temperatura do vidro e a interna do ambiente 6 . . 15

4.11 Valores das temperaturas dos vidros ao longo das horas. . . . . . . . . . 15

4.12 Valores das temperaturas internas ao longo das horas . . . . . . . . . . 16 


\section{Sumário}

1 Introdução teórica 1

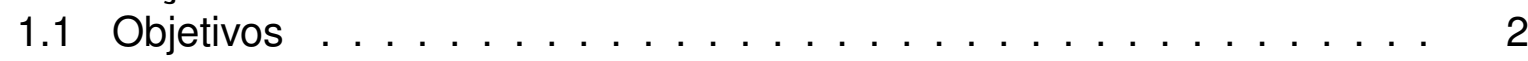

2 Fundamentação teórica 3

2.1 Películas aplicadas em vidros em fachadas . . . . . . . . . . . . . . . . 3

2.2 Atendimento ao certificado LEED . . . . . . . . . . . . . . . . . . . . . . 4

2.3 Efeitos luminosos em uma superfície transparente . . . . . . . . . . . . 4

2.4 O vidro com uma superfície de separação . . . . . . . . . . . . . . . . . 5

\begin{tabular}{lll}
\hline 3 & Metodologia & 6
\end{tabular}

4 Resultados e discussão 9

4.1 Luminosidade interna . . . . . . . . . . . . . . . . . . . . . . . 9

4.2 Luminosidade refletida . . . . . . . . . . . . . . . . . . . . . . . . . . . . 11

4.3 Estudo das temperaturas . . . . . . . . . . . . . . . . . . . . . . . . . . . . . . 12

4.4 Variação das tempeturaturas com o tempo . . . . . . . . . . . . . . . . 15

$\begin{array}{lll}5 & \text { Considerações finais } & 17\end{array}$

$\begin{array}{ll}\text { Referências Bibliográficas } & 19\end{array}$ 


\section{Capítulo 1}

\section{Introdução teórica}

Os vidros e as películas constituem cada vez mais as fachadas das construções, assim, fazendo cada vez mais parte da arquitetura contemporânea. É, portanto, um conceito moderno de beleza estética [1]. Além disso e por ser um material barato e de fácil aplicação, o vidro também permite grande uso da iluminação natural externa, principalmente em um país com grande insolação, como o Brasil, reduzindo a necessidade da utilização da iluminação artificial durante o período diurno.

A diminuição do uso da energia elétrica para iluminação tem como consequência a diminuição da conta de energia, que é um dos principais objetivos de todo consumidor, residencial ou comercial, já que segundo a ABRACE (Associação Brasileira de Grandes Consumidores Industriais de Energia e de Consumidores Livres) a estimativa é que no final de 2018, o aumento acumulado da conta de luz chegue a 44\% [2]. A despesa com a conta de luz, por exemplo, representa $17 \%$ do salário mínimo do brasileiro, como é apresentado em matéria da Energia Pura [3], o que é um valor muito alto a ser pago, e quando se tem alternativas acessíveis para a redução, como a utilização da iluminação natural, é de suma importância sua correta aplicação.

Para não se receber toda a energia do Sol, que pode fornecer uma iluminação muito forte para alguns ambientes, como escritórios, bem como aumentar demasiadamente a temperatura do ambiente interno, forçando a utilização de resfriamento artificial, uma solução encontrada foi o uso de películas aplicadas sobre os vidros. As películas envolvem a redução de transmissão de ondas eletromagnéticas para o ambiente interno, o que significa diminuição da temperatura ambiente e consequentemente na diminuição do ar condicionado, outro ponto de economia nos gastos mensais. Com isso, contribuem para o desempenho energético visando alcançar os parâmetros da Etiqueta Nacional de Conservação de Energia (ENCE), exigida pela Instrução Normativa $\mathrm{n}^{\circ} 2$ [4].

O uso de películas diminui a intensidade luminosa disponível [5, 6]. Se for muito escura pode fazer com que a necessidade da iluminação artificial aumente novamente. Trata-se portanto, de uma questão de equilibrar a entrada de luz e a entrada de calor no ambiente. Para isso, existem estudos sobre desempenho térmico e lumínico. Caso a película tenha grande índice de reflexão, pode-se gerar um aumento luminosidade e de calor nas vizinhanças da edificação. Esse efeito é acentuado se a geometria da fachada for curva, criando um ponto de foco para a luz refletida, com concentração dos raios eletromagnéticos e drástico aumento da temperatura e intensidade luminosa.

No projeto das partes iluminadas de ambientes, um fator a observar é a coloração do vidro que será utilizado. Vidros coloridos, como o azul e o verde possuem um apelo visual maior, no entanto podem acabar bloqueando as faixas visíveis do espectro da 
luz do Sol [7]. Isso também pode afetar a parte luminotécnica, por exemplo, com uma luz muito azulada sendo prejudicial para leitura ou causando grande estresse psicológico.

O tema da pesquisa não é muito estudado, principalmente no Brasil, mas de suma importância para a construção civil e para o desenvolvimento ambiental. As empresas construtoras não focam muito nesse aspecto na hora das construções, muitas vezes visando o material mais barato ou de maior apelo visual, sem um estudo do que cada tipo de material pode desempenhar. Apesar do impacto positivo no processo construtivo, a falta de estudos de adequação compromete os gastos futuros por aqueles que ocuparão e farão o uso dos espaços construídos.

\subsection{Objetivos}

O objetivo desse trabalho foi comparar o desempenho térmico e lumínico, do vidro float transparente, vidro de coloração verde, o vidro float transparente com película $50 \%$ de filtro e $75 \%$ de filtro e o vidro verde com as mesmas duas películas, com $50 \%$ e $75 \%$ de filtro filtro, em ambientes de escala reduzida, sendo caixas, de $1 \mathrm{~m}^{3}$, isoladas termicamente com madeira e isopor, com uma de suas faces abertas para a instalação dos vidros. Isso foi feito a fim de determinar a diferença de temperatura interna e externa de um ambiente reduzido e sua mudança ao longo do dia, para os diferentes tipos de vidro. Pode-se obter também, a relação da temperatura do vidro e a temperatura interna com o tempo. Outro intuito focado foi o estudo da luminosidade interna e refletida nos diferentes tipos de vidro e sua variação nas horas. Bem como a relação entre iluminação interna e variação da temperatura. $O$ estudo pode ajudar a reduzir 0 custo de obras, principalmente após o seu término, com a diminuição do consumo de energia, tanto com luz quanto com ar condicionado. Além disso, tem grande potencial para tornar uma obra comum mais sustentável. Podendo então, valorizar o custo do empreendimento ao adquirir certificados de sustentabilidade. 


\section{Capítulo 2}

\section{Fundamentação teórica}

\subsection{Películas aplicadas em vidros em fachadas}

Algumas características que as películas possuem dizem respeito a sua praticidade e economia. O tempo gasto para a sua instalação é rápido, que otimiza o tempo de obra, além de poder ser aplicada até mesmo após finalizado a obra, e gera quantidade de resíduos insignificantes. Além disso, possuem alta durabilidade e resistência. Por não haver metal em sua composição, não causam interferência em sinais de celulares.

Em artigo, Andreis, Besen e Westphal [8], realizaram estudos a fim de analisar o desempenho energético de fachadas envidraçadas em climas brasileiros. Eles constatam que o desempenho energético depende diretamente do tipo de vidro utilizado na fachada e do WWR (área da janela). Os tipos de vidros utilizados no trabalho foram os incolores, verde, laminado de controle solar e duplo de controle solar.

Lourenço, Glória Gomes e Moret Rodrigues, realizaram seus estudos visando o desempenho de vidraçados com películas de controle solar [6]. Concluíram que as películas modificam as propriedades ópticas de reflexão e transmissão solar. Afirmam ainda que as películas estão "contribuindo desta forma para melhorar as condições de conforto térmico e de iluminação no interior dos edifícios".

Já Diego Pizzutti realizou um estudo na UFRGS, consistindo na análise energética de edificações com uso de proteções solares [9]. Consta em sua conclusão, que uma determinada película, poly44, rendeu ao edifício uma economia de energia de $9 \%$, o que é um bom custo benefício quando seu uso é relacionado, por exemplo, com a utilização de controle de lâmpadas com cortinas do tipo corta-luz motorizadas, que reduz $18 \%$ os gastos energéticos, mas este possui um valor muito mais elevado. Portanto, mostra que a utilização de películas pode trazer um desempenho muito bom com um custo não tão alto.

A temática de desempenho térmico de vidros reflexivos através da medição do espectrofotômetro, alvo de estudo da Michelata, Medeiros e Castro [7], mostrou que vidros de determinadas cores transmitiam pouco e absorviam muito, e os incolores obtém propriedades inversas, alta transmitância e baixa absorbância. Ambos não atendem o objetivo do estudo, pois o ideal é alta luminosidade com baixa temperatura, mas com a utilização de vidros incolores com determinadas películas, alcança-se meIhor esse objetivo, uma menor transmitância mas também uma menor absorbância, que interfere no não aumento da temperatura interna, sem deixar o ambiente escuro.

Estudos realizados por Leite e Fernandes [10], tiveram como finalidade a avaliação da iluminação natural e artificial, assim como a eficiência energética do Ministério da 
Previdência Social / Trabalho e Emprego. Por causa da insuficiência das películas lá existentes, utilizavam as persianas fechadas, o que causou uma falta de iluminação, reflexão e ofuscamento, no $8^{\circ}$ andar. Uma solução achada foi utilizar a iluminação natural integrada com a artificial, trazendo eficiência energética e benefícios como redução do cansaço e fadiga visual por causa da luz natural.

A utilização da luz natural é também de grande importância para a diminuição do consumo de energia elétrica, como por exemplo de ar condicionado e principalmente de luz elétrica. Principalmente para edifícios comerciais onde a sua utilização acontece, geralmente nos momentos do dia em que há disponibilidade de luz natural, podendo assim utilizar o potencial energético que a natureza oferece.

O trabalho de Felippe [11], diz que a utilização de vidros na fachada para controle solar é uma alternativa financeira atraente. Além disso, outros fatores devem ser observados no momento da escolha da fachada, como por exemplo, a estética, permeabilidade visual e possível ocorrência de ofuscamento. Outro ponto observado é a alteração de iluminação artificial por iluminação natural.

\subsection{Atendimento ao certificado LEED}

O certificado LEED [12], em português "Liderança em Energia e Design Ambiental" é a principal plataforma utilizada para os edifícios verdes. Para se conseguir esse certificado, o edifício é avaliado e estes divididos em 4 tipologias. A película proposta no projeto pode ser utilizada em 3 das 4 tipologias. Uma diz respeito a Edifícios Existentes, caracterizando a sustentabilidade em algo já construído, e como películas são de fáceis instalações, fica acessível fazê-la, e tornando sustentável já que utilizará energia solar. Outra é Design de Interiores, visando a vista da natureza e iluminação natural, que conseguimos pela transparência do vidro e película. A terceira chama-se Novas Construções, onde visam parâmetros para construir um edifício que considere a sustentabilidade de maneira holística, onde a película ajudaria quando diz respeito a sua fachada. Segundo a LEED, a média de redução de energia elétrica do Brasil é a menor dentre as outras reduções comparadas, a redução de água, de CO2 e de resíduos. Além de ser um certificado reconhecido internacionalmente, ele contribui para a evolução do planeta. Pensando pelo lado financeiro, é algo muito vantajoso também, já que é um, certificado que aumenta o valor da sua construção.

\subsection{Efeitos luminosos em uma superfície transparente}

Para a medição da intensidade luminosa em um material transparente, nesse caso o vidro, é eficiente utilizar um luxímetro, que é um aparelho que quando a luz chega em seu sensor, determina em uma tela digital a sua iluminância, medida na unidade lux. Para medir, por exemplo, o reflexo que um vidro faz, basta apontá-lo em direção ao vidro, que a luz refletida pelo vidro será captada por ele. Um exemplo de aparelho, que foi o utilizado, é o Minipa MLM-1011. A iluminância, nada mais é que o fluxo luminoso que incide em uma superfície, por unidade de área, ou seja, uma luz visível. Resumindo, é a quantidade de luz que um ambiente possui. O lux, é uma unidade de medida que indica o nível de iluminância, assim mostrando o fluxo luminoso incidente sobre uma superfície. Esse valor é influenciado pelo comprimento da onda de luz e 
pela distância da fonte. Por não ser distribuído de maneira uniforme, esse valor varia de acordo com o ponto. O lúmen é uma unidade de medida de fluxo luminoso, que é a quantidade de luz emitida medida do ponto emissor [13].

A radiação solar, quando incide sobre a superfície, nesse caso o vidro, sofre três fenômenos ópticos que são a transmissão, absorção e reflexão [14]. A parte transmitida é a responsável pela iluminação interna mas também pelo aquecimento do ambiente [15], principalmente através da parte ultravioleta do espectro luminoso que é mais energética.

A parte absorvida pelo vidro também se converte em energia térmica, aquecendo a fachada do prédio, sendo mais uma contribuidora do aquecimento da edificação.

O fenômeno da convecção também pode ocorrer próximo a fachadas, pois o calor se propaga quando ocorre diferença na densidade dos fluidos do ambiente, causados pelas diferenças de temperaturas [14]. Portanto, com ar esquentando próximo aos vidros, devido a incidência da luz solar direta ou indireta, esse fenômeno pode permanecer durante um tempo mesmo depois do Sol se pôr, já que as correntes circulares de ar dependem da variação de temperatura do local, que pode aquecer o exterior do ambiente, além do interior já que pode haver absorção desse calor, por meio do vidro.

A parte refletida é devolvida para o meio externo, aumentando a temperatura e luminosidade externa. A reflexão em uma parede, pintada ou não, acontece de forma difusa. Dessa forma, espalha-se uniformemente por toda a região adjacente. Como efeito, é esperado um aumento na luminosidade local. Em um vidro, a reflexão é especular, tendo uma distribuição não uniforme. Isso significa que ela é muito concentrada em um ponto e quase nula nos outros pontos. Como efeito, a luminosidade ambiental devido à reflexão do vidro é muito menor, exceto por um ponto, que concentra muita luminosidade.

\subsection{O vidro com uma superfície de separação}

A capacidade térmica ou calor específico, define a variação térmica de determinada substância ao receber determinada quantidade de calor. A água, por exemplo, possui $1,0 \mathrm{cal} /\left(\mathrm{g}^{\circ} \mathrm{C}\right)$ de calor específico, enquanto o vidro possui $0,2 \mathrm{cal} /\left(\mathrm{g}^{\circ} \mathrm{C}\right)$ [16]. É uma quantidade pequena, ou seja, ele é um bom condutor térmico, que mostra que a quantidade de calor que ele recebe, ele deixa passar para o outro lado. Dessa maneira, quanto mais calor recebe, mais deixa transmitir para o meio interno do ambiente, e o faz rapidamente. Da mesma forma acontece quando o ambiente está frio. Por isso, em países frios eles utilizam camadas duplas de vidro, com a intenção de isolamento térmico, já que o ar que está entre os vidros serve como isolante [17]. Portanto, a aplicação de películas é uma das alternativas quando a intenção é o isolamento térmico, que nesse caso é a diminuição do calor interno. 


\section{Capítulo 3}

\section{Metodologia}

A proposta do trabalho foi reproduzir em escala o ambiente de uma sala de um edifício, o reduzindo e tomando medidas de temperatura e luminosidade interna e externa para entender as respostas dadas pelos diferentes vidros utilizados.

Foram usadas 6 caixas no total, com 1 vidro em cada, sendo 3 vidros transparentes float e 3 vidros verdes. Além disso, haviam 4 películas, 2 com $75 \%$ de filtro e 2 com $50 \%$ de filtro. Em um vidro transparente float foi colocado a película de $75 \%$ de filtro, no outro a película com $50 \%$ de filtro, o terceiro foi deixado sem película. Dessa mesma maneira foi feito com o vidro verde. A não utilização de películas nem muito escuras e nem muito claras, foi uma escolha que visou a utilização em prédios do dia a dia, pois acreditávamos ser as com melhor benefícios luminosos, para não escurecer muito e nem clarear muito, assim comparando películas intermediárias.

Para a realização das medições utilizamos placa de vidro com espessura de $6 \mathrm{~mm}$, largura e altura de $1 \mathrm{~m}$ acopladas a caixas cúbicas com arestas de $1 \mathrm{~m}$, construída com madeira nas suas faces (exceto aquela que recebeu o vidro). A face que está o vidro ficou exposta verticalmente e virada para o Sol. Uma representação da caixa pode ser vista na figura 3.1

A realização das medidas foram feitas em uma área aberta, sobre a grama, localizado no Bloco 11, do UNICEUB, localizado na SEPN 707/907, com coordenadas geográficas $15^{\circ} 45^{\prime} 55.85$ "S; 4753'50.59"O. Um esboço do local utilizado e da disposição dos ambientes reduzidos se encontra na figura 3.2. Nela, a numeração e disposição

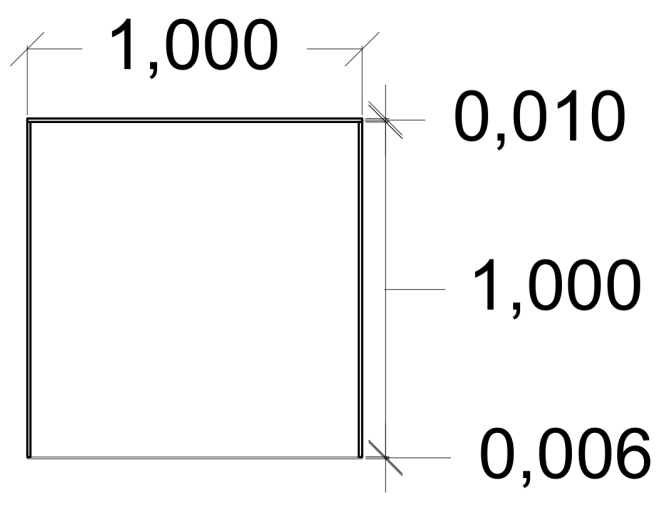

Figura 3.1: Representação em planta baixa das caixas que compõe o ambiente em escala reduzida. 


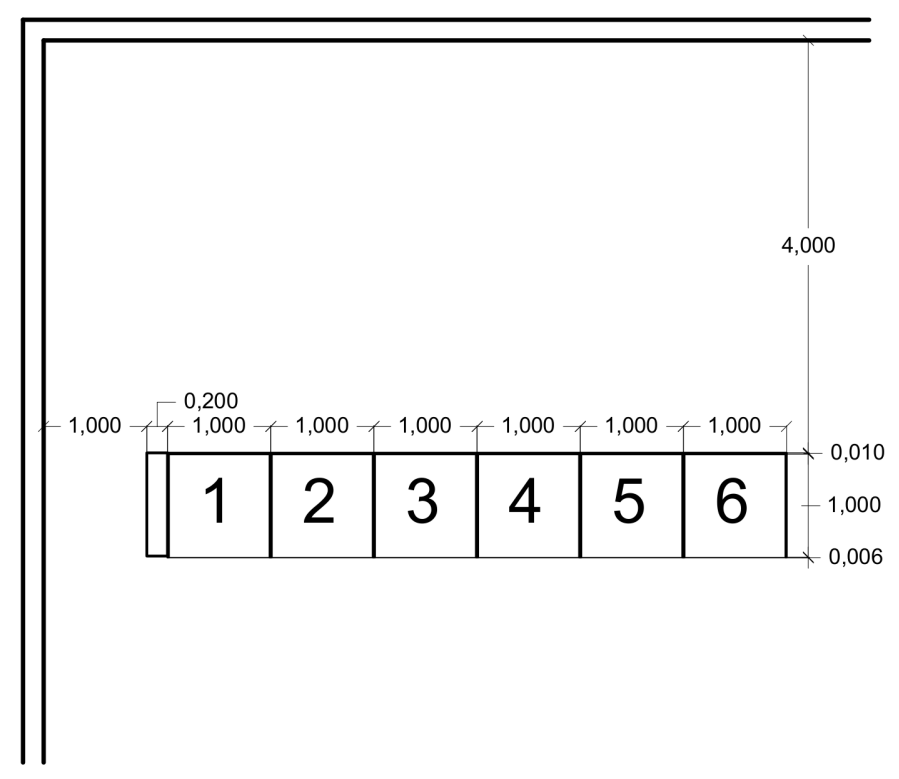

Figura 3.2: Esboço da disposição e numeração dos ambientes em escala reduzida.

das caixas é mostrada, bem como a posição aproximada dos muros, a um metro de distância da lateral da caixa um e quatro metros do fundo das caixas. Os vidros de cada caixa ficaram voltados para o lado oposto ao muro, portanto, na parte debaixo da figura. O leste se encontra à lateral da caixa 1 e o oeste voltado à lateral da caixa 6.

Os ambientes foram isolados termicamente com placas de isopor, na sua parte interna, conforme a necessidade. $O$ isolamento da caixa com o solo foi feito com a disposição de outras placas de madeira abaixo daquelas que formam o piso do ambiente, conseguindo assim um isolamento da camada de ar de $10 \mathrm{~cm}$. A maioria das caixas possuia contato lateral uma com a outra, exceto as caixas 1 e 6 . A caixa 1 foi encostrada numa estrura de $1 \mathrm{~m}$ de altura de alvenaria, já existente no local e com cerca de $20 \mathrm{~cm}$, composta de tijolo e reboco. A lateral externa da caixa $6 \mathrm{se}$ fez com as placas de isopor. Com isso, o calor transmitido pelo vidro era amplamente dominante.

Devido a limitações do local, as medições somente puderam ser realizadas no período da tarde, pois o muro lateral fazia uma grande sombra sobre as caixas. No entanto, o período da tarde se mostrou com ótima insolação. A declinação do Sol nessa época do ano fez com que a sua luz entrasse até muito próxima do fundo do ambiente, beneficiando as medições. Pela existência de construções do outro lado das caixas, uma sombra começava a se formar próximo das $16: 30$ na caixa 6 , tornando as medições inadequadas.

Utilizamos de duas metodologias para aferir os dados. Na primeira, utilizamos um tipo de vidro em cada caixa, colocados na seguinte disposição: na caixa 1, o vidro transparente, na caixa 2 o vidro verde, na caixa 3 o vidro transparente com filtro de $50 \%$, na caixa 4 o vidro transparente com película de $75 \%$, na caixa 5 o vidro verde com filtro de $50 \%$, na caixa 6 o vidro verde com película de $75 \%$. As medidas de luminosidade e temperatura foram tomadas a cada meia hora. Para tentar encontrar os mesmos resultados e eliminar fatores ambientes, fizemos as mesmas medições de maneira diferente. A cada meia hora um vidro era colocado na frente da caixa 4 , as medidas eram feitas e o vidro trocado. Seguindo-se, com os seis vidros durante 0 
período da tarde.

As medidas de luminosidade do ambiente foram feitas com um luxímetro, sempre com seu sensor voltado para o lado oposto do sol, ou seja, voltado para o muro que estava a cerca de $4 m$ das caixas. O sensor era posicionado cerca de $0,5 m$ acima do topo das caixas. Com o mesmo aparelho, foi medido a reflexão luminosa de cada vidro, sempre apontando o sensor para o centro dos vidros, a $1 \mathrm{~m}$ de distância deles, com o cuidado de não estar produzindo sombra na frente do vidro. Também foram realizada medidas da luminosidade interna das caixas, abrindo uma pequena fresta na parte posterior da caixa e apontado o sensor para frente, no centro da caixa a uma altura de cerca de $0,9 \mathrm{~m}$ e encostado na face oposta ao vidro.

Para as medidas de temperatura utilizamos uma câmera térmica. Para a medição da temperatura do vidro, foi apontado a câmera a $1 \mathrm{~m}$ de distância e focado no centro do vidro. Para a sua temperatura interna, utilizou-se da mesma abertura posterior utilizada para as medidas de luminosidade e as medidas foram tomadas no canto posterior da caixa, aproximadamente num quadrado de $20 \mathrm{~cm}$ por $20 \mathrm{~cm}$ do fundo, tendo-se o cuidado de se pegar as medidas sempre na mesma posição, em todas as caixas.

Todas as medidas foram feitas sistematicamente, repetindo-se 10 vezes as mesmas medidas e tomando-se a média, de acordo com a equação

$$
\bar{x}=\sum_{i=1}^{N} \frac{x_{i}}{N},
$$

sendo $N$ o número de medidas realizadas. Também foram calculados os erros aleatórios através do desvio padrão,

$$
\bar{\sigma}=\sqrt{\sum_{i=1}^{N} \frac{\left(\bar{x}-x_{i}\right)}{N}} .
$$

Como os aparelhos eram digitais, os erros instrumentais eram a própria menor medida do aparelho: $0,1^{\circ} \mathrm{C}$ para a câmera térmica e $1(x 10 l u x)$ para o luxímetro. Assim, cada conjunto de medidas consistiu do seu valor médio com desvio do erro total, a soma do erro aleatório com o erro instrumental: $x=\bar{x} \pm \Delta x$.

Todos os dados de medição foram inseridos no MS Excel para os cálculos de média e desvio padrão. Para os gráficos, utilizou-se o próprio MS Excel bem como o Gnuplot. Foram feitos diversas tabelas e gráficos com a junção das diferentes comparações. Considerando os mesmos vidros, as medidas de uma mesma hora dos vários dias foram utilizadas para se calcular uma média final, com seus respectivos erros associados. 


\section{Capítulo 4}

\section{Resultados e discussão}

Nessa seção, será mostrada uma análise detalhada dos resultados obtidos a partir das medidas tomadas. Por brevidade, nos referiremos somente a expressão vidro 1 para encurtar algumas expressões que podem significar vidro mais película, seguido do número da caixa em que o vidro foi colocado na metodologia 1 . E para que o leitor não precise retornar aos capítulos anteriores repetidamente, relembraremos que o vidro 1 é o vidro transparente, o vidro 2 é o vidro verde, o vidro 3 é o vidro transparente com filtro de $50 \%$, o vidro 4 se refere ao vidro transparente com película de $75 \%$, 0 vidro colocado na caixa 5 é o vidro verde com filtro de $50 \%$, e finalmente, na caixa 6 foi utilizado o vidro verde com película de $75 \%$.

\subsection{Luminosidade interna}

Com a disposição dos vidros e das caixas dada pelo método 1, descrito na metodologia, em que todos os vidros são expostos ao Sol ao mesmo tempo, pode-se obter o gráfico da figura 4.1. Os valores de cada barra se referem à média dos valores médios apurados em cada dia. E as faixas vermelhas em cima de cada barra indicam o erro propagado, a partir do desvio padrão da média, calculados a partir dos erros totais de cada dia.

Percebe-se que o vidro 1 foi aquele que mais deixou o ambiente interno claro, ou seja, que mais deixou luz solar entrar. Esse é o vidro transparente e sem película. Esse resultado era esperado, por não ter nenhum filtro aplicado sobre esse vidro. Visualmente o resultado também era óbvio, pois aparentemente a iluminação interna era a mesma da externa. O vidro 2, por sua vez, apresentou uma luminosidade interna muito parecida com a do vidro 1, no entanto foi capaz de atenuar um pouco o efeito do Sol por si só. Já o vidro que mais diminuiu a luminosidade interna, ou seja, o ambiente mais escuro foi o vidro 4, com uma luminosidade ainda menor do que a do vidro 6 . Nesse caso o resultado não era tão óbvio pois os dois possuiam a mesma película. Até era esperado que o vidro 6 pudesse ter a maior queda na luminosidade, mas não foi o que ocorreu nesse caso. Na comparação entre os vidros 3 e 5, esperava-se que as suas luminosidades também fossem próximas. Entretanto, a diferença entre eles foi de aproximadamente 1000 (mil) lux, uma quantidade considerável. De acordo com o método 2, apresentado na figura $4.2 \mathrm{em}$ que todos os vidros foram colocados alternadamente na caixa 3 , os resultados foram muito similares, confirmando os fatores de iluminação do método 1. 


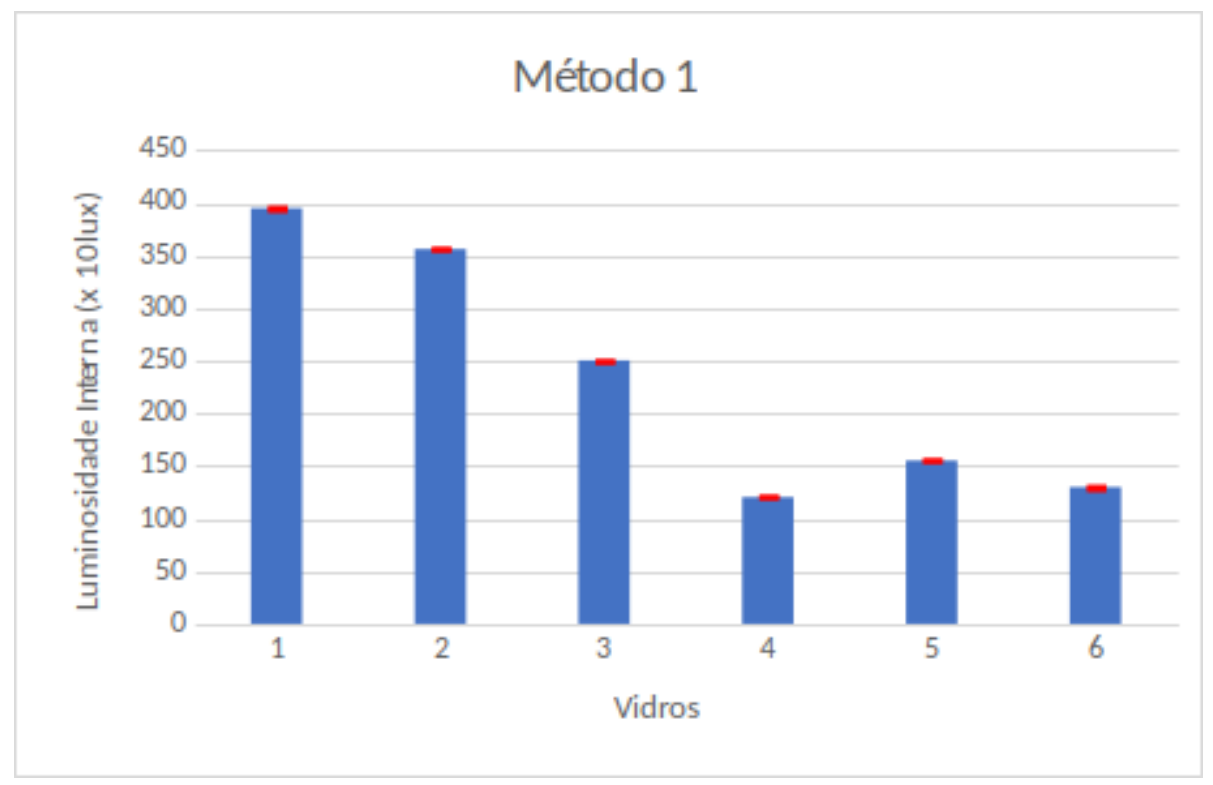

Figura 4.1: Luminosidade interna medida no ambiente de escala reduzida, para cada vidro, utilizando-se da metodologia 1.

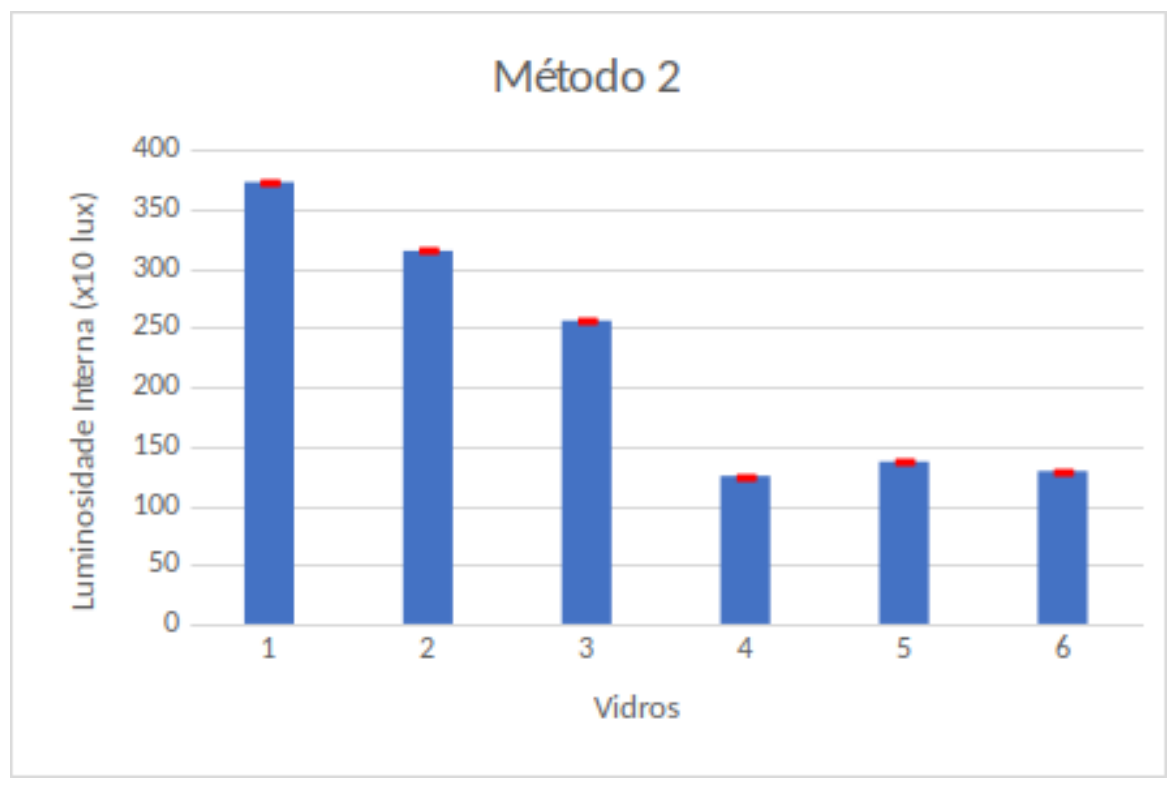

Figura 4.2: Luminosidade interna medida no ambiente de escala reduzida, para cada vidro, utilizando-se da metodologia 2. 


\subsection{Luminosidade refletida}

O gráficos da luminosidade refletida, utilizando-se o método 1, é mostrado na figura 4.3. Aqui, os resultados mostram que o vidro 1 foi o que mais refletiu, tendo um decréscimo da luminosidade refletida em direção ao vidro 6 . Esse resultado, observado ao longo dos dias da medição, estava em descordo com o esperado. $O$ vidro 1 deveria ter a maior transmissão mas não a maior reflexão. Visualmente, isso também não era o que se observava. Esse foi um dos motivos que nos levou a montar uma outra metodologia de medição, a metodologia 2. Nessa nova metodologia, com resultados explicitados na 4.4, o vidro com maior reflexão foi o vidro 4. Os vidros com película, na verdade, apresentaram reflexão muito superior àquela do vidro transparente (vidro 1). Mesmo assim, o vidro 2 continuou com alto índice de reflexão.

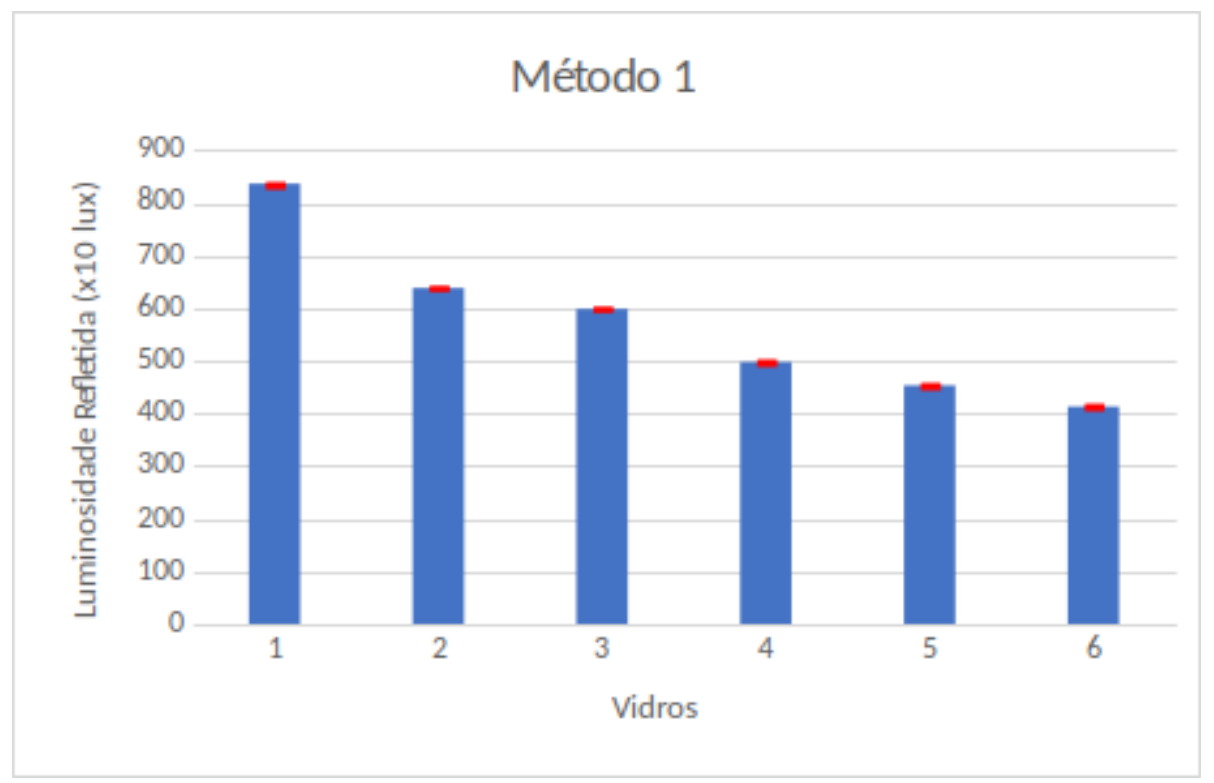

Figura 4.3: Luminosidade refletida por cada vidro, utilizando-se da metodologia 1.

Percebeu-se, então, que o desvio mostrado na metodologia 1 provavelmente é gerado pelo muro lateral, de cor branca e alto brilho. O efeito esperado do muro, nessas condições, é exatamente a luminosidade ir caindo com relação à distância, o que é observado na figura 4.3 . Quando essa distância foi mantida constante, na metodologia 2, os resultados variaram bastante. Outra informação que nos possibilitou chegar a essa conclusão é a medida da luminosidade em frente aos vidros e aquela tomada acima deles. Enquanto a luminosidade na frente dos vidros não chegou a ultrapassar os 7 mil lux em nenhuma das metodologias, a luminosidade acima dos vidros quase nunca era menor do que 10 mil lux, chegando próximo de 20 mil lux em muitas medições. Essa diferença pode ser atribuida ao muro localizado no fundo das caixas, mesmo este se encontrando a cerca de 4 metros de distância. Visualmente, a luminosidade do muro passava a impressão de ser maior também. Além disso, pela teoria e como explicado na fundamentação teórica, uma superfície difusa tente a ter uma luminosidade refletida efetivamente maior, mais uniformemente distribuída, enquanto superfícies envidraçadas tem uma luminosidade menos uniforme, sendo elevada somente em um único ponto. 


\section{Método 2}

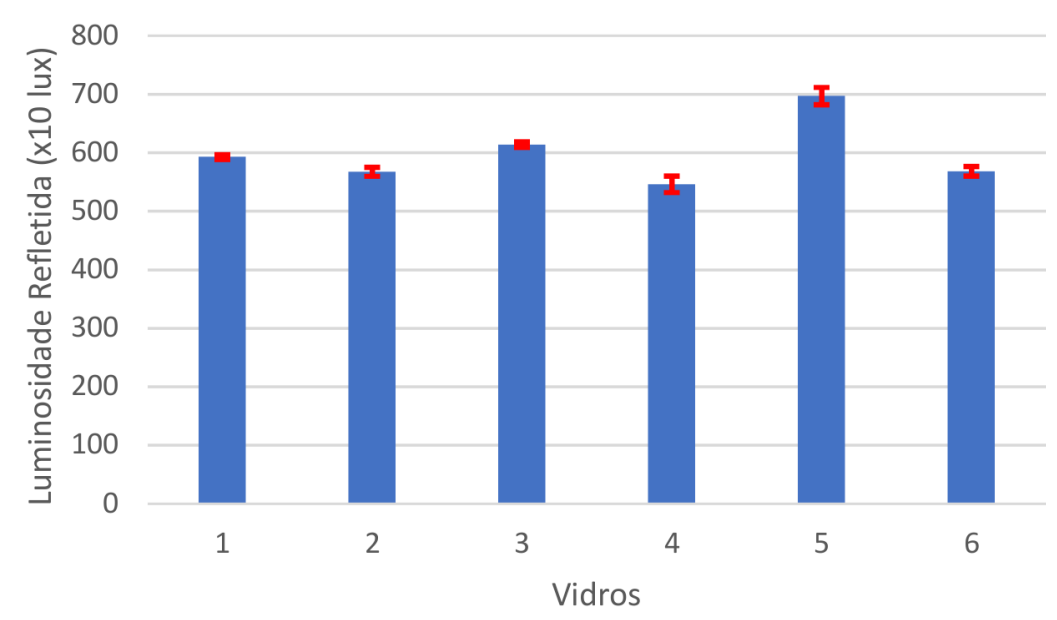

Figura 4.4: Luminosidade refletida por cada vidro, utilizando-se da metodologia 2.

\subsection{Estudo das temperaturas}

Nesta seção serão mostradas a comparação entre as temperaturas dos vidros e de seus ambientes internos. As horas do dia são mostradas em um formato que dá impressão de que os minutos poderiam ir até 100 . No entanto, cada hora só tem 60 minutos. Esse desvio no eixo do gráfico, não prejudica em nada a nossa análise, pois não tem-se como objetivo fazer uma interpolação dos pontos do gráfico. No gráfico 4.5. percebe-se que as $13 \mathrm{~h}$, logo na colocação do vidro, a temperatura interna era elevada e o vidro, ainda com pouca exposição ao Sol, estava relativamente frio. Com cerca de meia hora de exposição, as temperaturas se equilibraram. $O$ vidro 1 aqueceu e diminuiu a temperatura interna. Apesar disso, a temperatura interna se manteve igual à temperatura do vidro. Isso mostra que o vidro 1 transmite ao interior grande parte da energia que recebe. Essa informação é corroborada pelo gráfico da figura 4.1. que mostra que grande quantidade de energia luminosa passa para o ambiente.

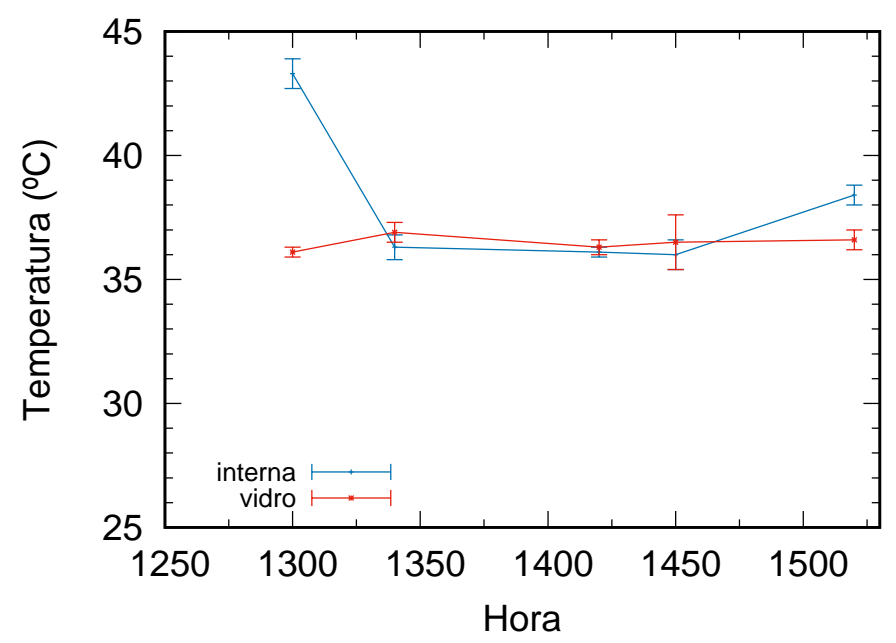

Figura 4.5: Comparação entre a temperatura do vidro e a interna do ambiente 1 


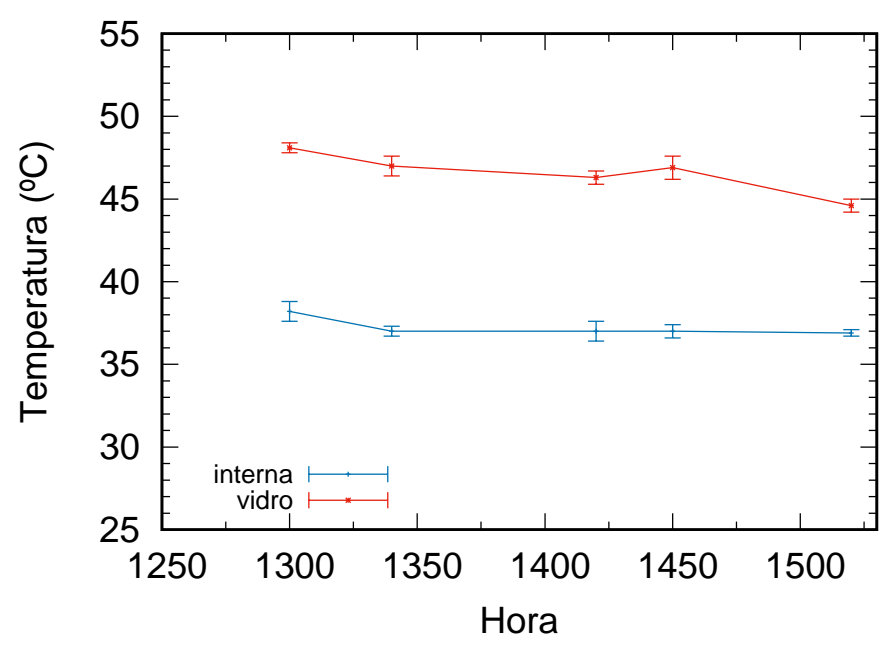

Figura 4.6: Comparação entre a temperatura do vidro e a interna do ambiente 2

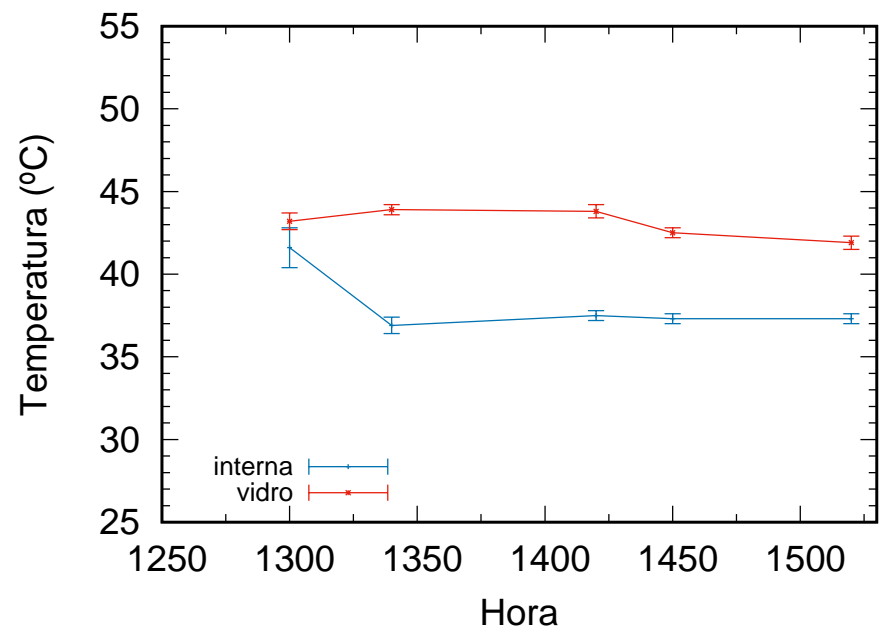

Figura 4.7: Comparação entre a temperatura do vidro e a interna do ambiente 3

O vidro 2 é um vidro que aqueceu rapidamente, como mostrado na figura 4.6. Além disso, manteve temperaturas muito mais elevadas ao longo de toda a tarde, mais altas do que a do vidro 1. A atenuação da temperatura do ambiente foi fraca, sendo que esta temperatura está próxima daquelas medidas no ambiente 1, mostrado na figura 4.5 .

No terceiro ambiente, as temperatura internas também foram da ordem de grandeza dos casos anteriores. A temperatura do vidro, no entanto, foi mais baixa do que apresentada pelo vidro 2 . A película de $50 \%$ mostra-se portanto não muito eficaz no quesito de baixar a temperatura interna.

A quarta caixa foi capaz de baixar a temperatura interna do sistema, e essa temperatura foi se reduzindo ao longo do dia. No entanto, a diferença de temperatura não foi muito significativa, permanecendo sempre acima dos $35^{\circ} \mathrm{C}$. Mesmo uma película mais forte não foi o suficiente para diminuir significativamente a temperatura, ao custo de uma perda de luminosidade muito grande, como mostrado nas figuras $4.1 \mathrm{e} 4.2$.

$O$ vidro 5 apresenta uma grande diferença de temperaturas entre o vidro e a parte interna. Também possui temperaturas internas um pouco mais baixas do que os outros 


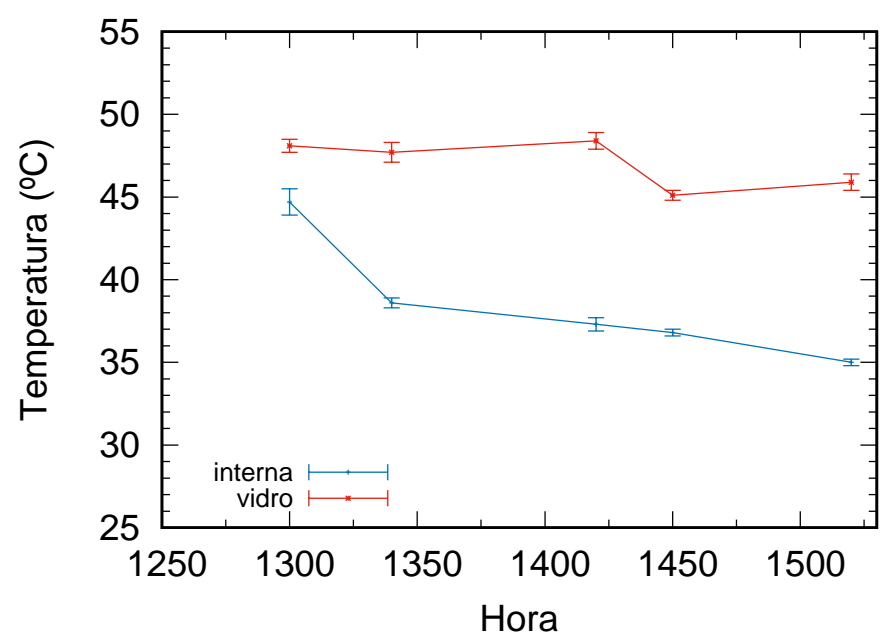

Figura 4.8: Comparação entre a temperatura do vidro e a interna do ambiente 4

casos, baixando de $35^{\circ} \mathrm{C}$ ao longo do dia.

Aquele que obtve mais sucesso no resfriamento foi o vidro 6 . Suas temperaturas foram sistematicamente menores do que $35^{\circ} \mathrm{C}$, diminuindo ainda de $30^{\circ} \mathrm{C}$. Essa tendência se mantém mesmo no horário das 14:50, quando o vidro ainda apresenta uma temperatura elevada. A medição feita após as $15 \mathrm{~h}$, nesse caso, foi comprometida pela sombra do edifício vizinho que se formou sobre ela, derrubando tanto a temperatura interna quando a do vidro.

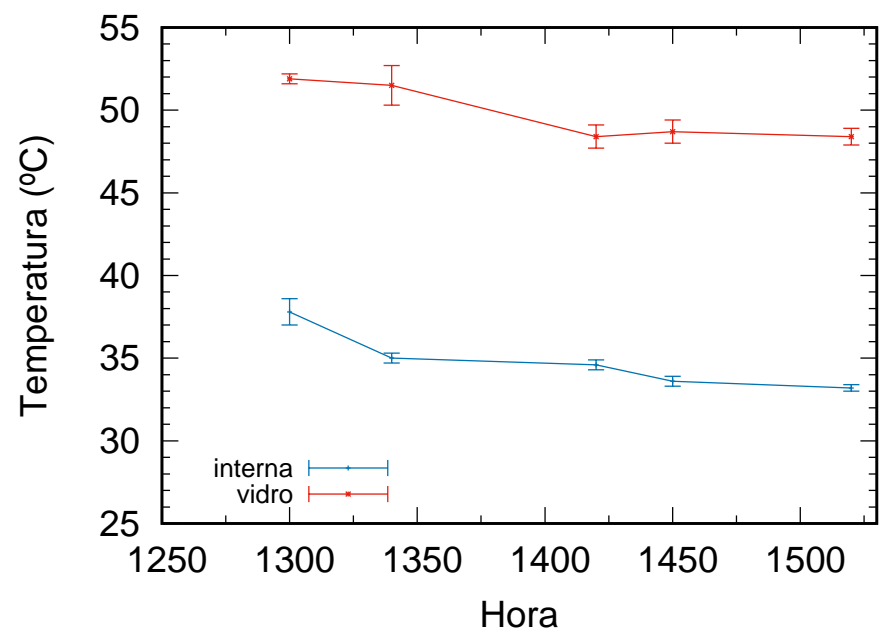

Figura 4.9: Comparação entre a temperatura do vidro e a interna do ambiente 5

O que se percebe pelos gráficos, é que as películas aumentam o poder de absorção de calor dos vidros, todos mostrando temperatura elevada. No entanto, o aumento da absorção e a diminuição da luminosidade interna não mostram uma redução da temperatura interna efetiva, a não ser pelo caso do vidro 6 , que teve temperaturas um pouco mais baixas. Uma das explicações possíveis, é que apesar de filtrar luz visível, as películas ainda deixam passar uma parte do ultravioleta. Outra explicação é que o calor a mais absorvido pelos vidros também acaba contribuindo para o aquecimento do ambiente. 


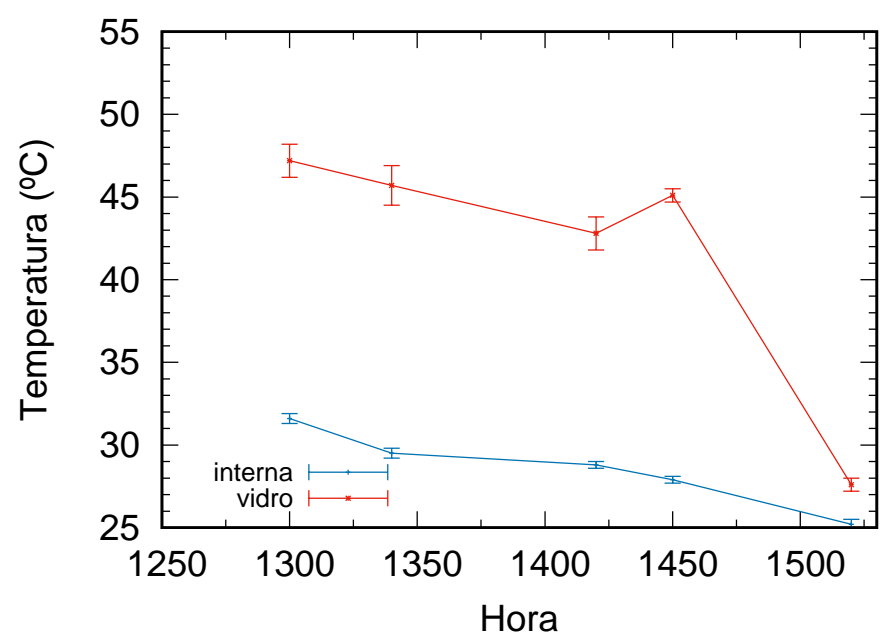

Figura 4.10: Comparação entre a temperatura do vidro e a interna do ambiente 6

\subsection{Variação das tempeturaturas com o tempo}

Para analisar a influênia das horas do dia na temperatura dos ambiente, analisouse dados de temperatura em função do tempo transcorrido, comparando todos os vidros de uma só vez. Na figura 4.11, as temperaturas dos 6 vidros foram mostradas juntas. O vidro 1 foi o vidro que menos se aqueceu com o Sol. Provavelmente esse fato se deve a esse vidro transmitir a radiação recebida, quase sem absorver energia quando comparado aos vidros coloridos ou com película aplicada. Estes últimos, por sua vez, motraram grande absorção de calor, tendo temperaturas sistematicamente mais elevadas.

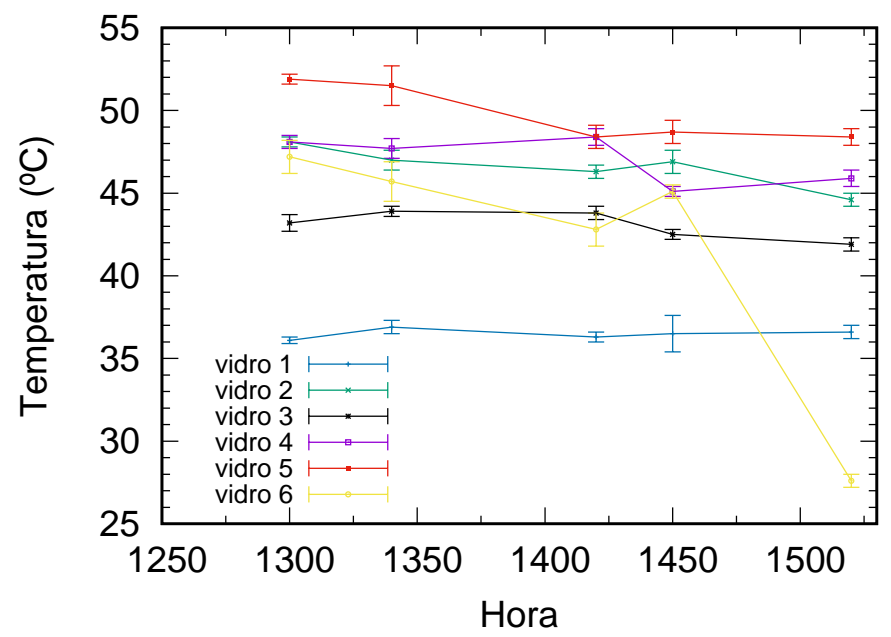

Figura 4.11: Valores das temperaturas dos vidros ao longo das horas

Quanto à temperatura interna, é notório pelo gráfico da figura 4.12 que o vidro 6 apresentou os melhores resultados. $O$ vidro 5 também foi capaz de boa redução de temperaturas. Os outros vidros apresentaram resultados muito próximos. 


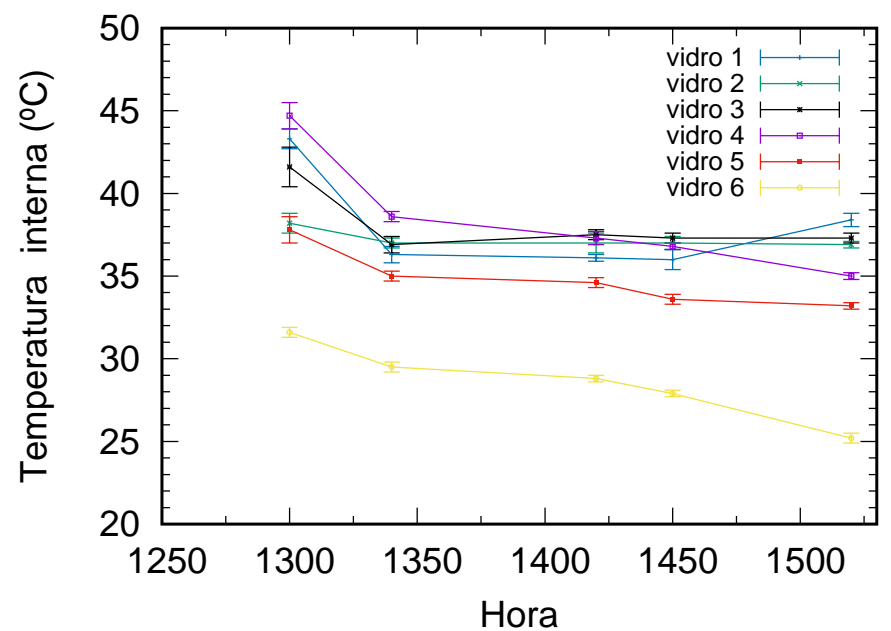

Figura 4.12: Valores das temperaturas internas ao longo das horas 


\section{Capítulo 5}

\section{Considerações finais}

A partir dos dados analisados e pelos gráficos gerados, foi observado que que a aplicação das películas nos vidros podem apresentar grande redução de luminosidade nos ambientes internos. Mas nem sempre essa queda está associada a uma queda de temperatura do ambiente interno. A cor do vidro utilizado também pode influenciar nos resultados de luminosidade, no entanto a aplicação de películas diminui a diferença nos parâmetros dos vidros associados às cores, sendo mais forte a influência das películas.

Dessa forma, um projeto pode optar por aplicar sobre um vidro transparente uma película que resultará em menor luminosidade interna quando se trata, por exemplo, da fachada de uma biblioteca, ou maior luminosidade, quando se trata de um escritório. $E$ que essa escolha possui pouca influência na temperatura interna do ambiente. Por outro lado, essa influência é mais significativa se os vidros aos quais as películas serão aplicadas forem verdes.

Percebeu-se também que apesar da grande absorção de calor e, consequentemente, grande temperatura dos vidros verdes ou com películas aplicadas, isso não resulta em temperaturas internas maiores, como talvez se pudesse esperar. $O$ calor do vidro se mantém constante ao longo do dia, bem como a temperatura interna dos ambientes, não existindo troca de calor significativa entre os dois, exceto talvez, por áreas muito próximas ao vidro. De fato, a diferença de temperaturas dos vidros podia ser sentida quando se encostava neles.

Apesar das películas apresentarem boa taxa de reflexão, bem maiores do que as dos vidros transparentes, essa reflexão ainda é baixa quando comparada à reflexão de uma superfície difusa como a de um muro branco. Portanto, um edifício pintado, especialmente de cores claras, tenderá a aumentar mais a reflexão ao seu redor do que um edifício composto de grande quantidade de vidros em sua fachada. No entanto, não deve-se relativisar os problemas associados à reflexão dos vidros e películas, uma vez que em algum ponto, que pode ser no solo, a reflexão especular concentrada dos vidros pode ser altamente prejudicial, por exemplo, se o foco da reflexão ocorrer em outro edifício, aumentando muito a luminosidade e calor em ambientes alheios.

Neste trabalho, ficou mais claro que a temperatura interna de um ambiente pode ser substancialmente reduzida, como aconteceu com a película de $75 \%$ de filtro sobre um vidro verde, mas que isso foi acompanhado de grande perda na intensidade da iluminação natural. Pode-se especular que essas películas não trabalham bem nas faixas do infravermelho e ultravioleta, bloqueando muito da luz visível do espectro, sem bloquear o calor eficientemente.

Trabalhos futuros sobre as películas ainda são necessárias. Apesar dos resultados 
obtidos, estes podem variar também de acordo com o fabricante de cada película. No entanto, o preço também pode variar muito. É sempre necessária uma análise cuidadosa da relação custo-benefício, principalmente se o único desempenho das películas forem diminuir a luminosidade interna, o que na maioria dos casos, não é desejado. 


\section{Referências Bibliográficas}

[1] V. MCLEOD. Detalhes Construtivos da Arquitetura Contemporânea com Vidro. Bookman, São Paulo, 2012.

[2] Lais LIS. Conta de luz acumula alta média de 31,5\% entre 2014 e 2017, diz estudo. Portal G1, <https://g1.globo.com/economia/noticia/conta-de-luz-acumulaalta-media-de-315-entre-2014-e-2017-diz-estudo.ghtml>, 2018.

[3] ____._. Sabia que você trabalha 11 horas no mês só para pagar a conta de luz? Energia Pura, <https://energiapura.com/pagar-a-conta-de-luz/>, 2014.

[4] Instrução normativa $n \quad 2$, de 4 de junho de 2014. Ministério do planejamento, desenvolvimento e gestão, $<$ http://www.comprasgovernamentais.gov.br/paginas/instrucoesnormativas/instrucao-normativa- no-2-de-4-de-junho-de-2014>, 2014.

[5] P. F. M. MARTINS. Estudo da influência do tipo de vidro na temperatura interna em modelos reduzidos em Brasília. UniCEUB, Brasília, 2016.

[6] M. G.; RODRIGUES A. M. LOURENÇO, D.; GOMES. Estudo experimental do desempenho de envidraçados com películas de controlo solar. 2016.

[7] J. F.; CASTRO A. P. A. S. MICHELATA, R.; MEDEIROS. Avaliação do desempenho térmico de vidros refletivos através de medições em espectrofotômetro. 2006.

[8] P.; WESTPHAL F. S. ANDREIS, C.; BESEN. Desempenho energético de fachadas envidraçadas em climas brasileiros. 2014.

[9] D. PIZZUTTI. Análise energética de edificação com uso de proteções solares. 2010.

[10] J. T. LEITE, L.S.; FERNANDES. O desempenho da iluminação natural e artificial de ministério em brasília: Diretrizes e recomendações para o conforto visual do usuário e otimização energética. 2013.

[11] A. R. FELIPPE. Desempenho luminoso e energético de vidro de controle solar e dispositivo de sombreamento. 2016.

[12] ___._. Certificação LEED. Green Building Council Brasil, São Paulo, 2014.

[13] ___._. Manual de iluminação - Eficiência energética nos prédios públicos. Procel EPP, 2011. 
[14] PAUL G. HEWITT. Fundamentos de física conceitual, volume 1. Bookman, Porto Alegre, 2008.

[15] R. B.; SANDS M. FEYNMAN, R. P.; LEIGHTON. Lições de Física de Feynman: a edição definitiva, volume 1. Bookman, Porto Alegre, 2008.

[16] G. D.; DIAS H. BAUER, W.; WESTFALL. Física para universitários: relatividade, oscilações, ondas e calor. AMGH, São Paulo, 1 edition, 2013.

[17] F. S. BESEN, P.; WESTPHAL. Uso de vidro duplo e vidro laminado no brasil: avaliação do desenvolvimento térmico por meio de simulação computacional. 2012. 